\title{
Against Speed Cosmopolitanism towards the Slow University
}

\author{
Jeremy Hunsinger
}

\section{Introduction}

As I sit at my desk working on this paper, the world continues accelerating. It is a nihilistic acceleration; without patience; without prudence; toward a forgetting of the very reasons for the acceleration in the first place. This acceleration is the backbone of contemporary risk society and the risk society's related knowledge society(Beck, ; Beck, 1992). The ideology of speed cosmopolitanism is our universalizing justification of accelleration in relation to our lives as individuals and members of greater and global wholes. At the core of that ideology is its technicity, which is perhaps best exemplified in the internet. The internet is a network of networks or system of interconnected networks, computers, peoples, agents, and programs. The internet enables and to some extent incorporates the ideology of speed cosmopolitanism as it enables faster and faster communication amongst a global population, transforming their relations through accelleration.

The internet's technicity is operationalized within speed cosmopolitanism as both a system of real or virtual travels and travails of knowledges and knowledges' communities; as a system of knowledge construction and communication. But the internet's relations to the communities of contemporary construction of knowledges also enables us to use it to resists the accelerations of speed cosmopolitanism. This consideration of knowledge and its construction in relation to the internet brings me to the idea that is central to this paper, and that is that knowledge is not fast, knowledge grows fast but its growth is primarily due to population and population's multiplications, and not due to speed cosmpolitanism and technocultural acceleration of its technicities. Coming to know is not fast, nor is it becoming faster, and while new technologies aid us in creating knowledge and the larger communities engaged with questions might create a simulation of acceleration of knowledges, the communal nature of knowledge and the trust we build into knowledge limits its speed of personal and communal knowledge production and acquisition. The tension between the perceived need for the acceleration of knowledge construction and acquisition and the reality of the process is the generative thesis of this paper.

As the slow science manifesto says:

We do need time to think. We do need time to digest. We do need time to misunderstand each other, especially when fostering lost dialogue between humanities and natural sciences. We cannot continuously tell you what our science means; what it will be good for; because we simply don't know yet. Science needs time. http://www.slow-science.org/

Science is one mode of coming to know, and those performing that mode need time to think, time to engage with prior knowledges, time to engage with others in relation to that knowledges, and time to build more knowledge. Coming to know, as the primary process of knowledge, is a mobile, communal and material effort, and it engages people, places, and things, through our memories and practices tied to the histories of knowledges, its fluxes, and its futures. The processes of knowledge as such are not easily co-constructed in any meaningful or passionate relation without considerations of time and time's passing. Since the rise of the culture of speed cosmopolitanism after World War 2, there have been numerous attempts to provide learning spaces that allow for knowledge to be co-constructed in consideration of time and thus to be built well, with all of its normativities encapsulated and 
planned. Similarly various colleges and universities have been created with that mindset, and many alternatives to those institutions have also been created; some have failed and some have flourished. This paper posits and follows yet one more possibility, a possibility that resists the idea that knowledge production and acquisition is fast, that knowledge can be a commodity, and that knowledge can be formalized and packaged into consumable degree that meets a determined schedule and as such exists only in relation to the economic and efficient necessities. Instead I argue that knowledge should be constructed in relation to one's life, one's community, and with an eye toward the global future. This requires us to slow knowledge production and acquisition down, to reimagine the institutions of knowledge production and to redesign, or perhaps even explode the university as we know it in order construct the slow university.

\section{| Speed Cosmopolitanism and Its Technologies in the Context of Hypercapitalism}

Speed cosmopolitanism globalizes the transformative accelerations of capitalism as a normative ideology. It claims that we should be fast, move fast, decide fast, and if anything we should do them faster as exemplified by global business literatures(Jennings \& Haughton, 2002; Gates, 1999; Gleick, 2000). Speed cosmopolitanism highlights a generalized strategic vision of how to take advantage of other people being slower and thus implies we should always be quicker. As it globalizes, speed cosmopolitanism transforms global value systems, reconfiguring those systems in relation to speed and acceleration culture. As an assemblage of our social imaginations; speed cosmopolitanism entails the alienation of elements of our subjectivity through the reimagining and resubjectifying of elements of ourselves withing the context of the necessities of relative acceleration and speed.

Being quicker, as the ideology demands, can be and frequently is a strategic disadvantage in our lives as consumers and our lives as learners due to the limiting frameworks in which we exist. These limits constrain our ability to be quick in a strategic manner because they limit what we can know before we act. To act strategically in our best interests, we already must know what is best or at least we need to know the heuristics of discovering the optimal bestness within the framesworks of speed cosmopolitanism. If we don't have those heuristics or the knowledge to operate without them, we must find ways to construct or constrain our environments to provide us with the strategic advantage. However, speed ablaits our efforts, and frequently it is not possible to reconstruct the environment to our advantage when moving at speed.

Without the ability to change the environment or our situatedness in relation to our strategic speed, we are left with the only thing left to change, ourselves. This re-construction of our subjectivity first imagines, then re/creates human beings as strategic fast-moving, machinic, individualities that must operationalize within themselves a strategic daemon optimized for our own capacities at performing decisions based on limited and imperfect information, we become calculating machines in ourselves and could be best thought of less as humans in that light, then as information processors like computers(Beck-Gernsheim \& Beck, 2002; Guattari, 1995; Guattari, 1996). This is the model of homo economicus in speed cosmopolitanism, we become the creators and operators of robots inside of ourselves that manage the optimizations that the accelerating world requires.

These operationalized robots function as our primary adaptation to speed cosmopolitanism and they govern our everyday lives in those contexts. This makes our bodies into the defacto zombies of hypercapitalism, in which our subjectivities are primarily robotized responses to stimuli and ensconced within our streams of informational stimuli. We seldom find time to escape into any critical or reflective mode of thought that would actually allow us to transform our lives toward actual creative thought leading to innovations. That escape would be resisted socially as it would make the whole system remarkably inefficient at precisely what the system is supposed to be becoming efficient. In the case of universities, those efficiencies would be the operationalizations surrounding the markets of information and knowledge being constructed as their replacement in neoliberalism(Olssen \& Peters, 2005).

Speed cosmopolitanism is a form of hypercapitalism which could be thought of as one form of trans-temporal neoliberalism(Graham, 2001; Pedersen \& Nielsen, 2013; Reid, 1978). As neoliberalism, it attempts to formalize markets where none exist by transforming systems, processes and/or thoughts into commodities. This neoliberalism assumes these markets are just systems of exchange for mutual profit, and all goods are about profit. (Habermas, 2000) These markets of thought and process like all markets center on questions of information and the lack of perfect information. Thus in neoliberalism we construct a system of informationally biased 'free' trading within those markets which given the imperfections of information is anything but free and likely anything but just. This 
lack of freedom is comparably exploited by those with more information, who are theoretically more free. But in this hypercapitalist environment, these 'free' traders need to act before their private information propagates to others thus becoming public information.

The need for speed in neoliberal environments created the hypercapitalist tendency that is the trans-temporality of neoliberalism and thus the promotion of the imaginary over the reality in our market environments $(\mathrm{Graham}$, 2001; Massumi, 2005). While the imaginations are important to consider, the central operation of the re/creation of realities through those market operationalizations in speed cosmopolitanism plays within the both the technesis and technics of hypercapitalism, from the computers and their programmable systems trading shares faster than humanly capable, to prediction markets predicting future actions, and the statistical systems that support all the technics of hypercapitalism within their normal and non-normal frameworks. These technics/techneses operate both historically and in the future across our normal experiences of time, creating the trans-temporal space of activity through which our markets of knowledge will operate. We can already see this with the subtle editing of systems like wikipedia by certain groups use those technics to alter our understandings ever so slightly, while other groups create a plurality of competing sources of knowledges, each with their own biases. These movements toward the past and its projection to future systems are policy decisions by groups and individuals that then are read by the computational engines aiming at providing accurate models. Hypercapitalism's trans-temporality operates through the systems, organizations, processes and thoughts that neoliberalism is transforming into markets through our own actions(Feldman \& Feldman, 2006).

Hypercapitalism is not the only trans-temporal system to occur in the world, indeed most systems have transtemporal elements. But I should be clear here, by trans-temporal, I do not mean eternal in the religious sense. Transtemporal means some process is cutting through and across temporalities and thus through and across speeds and the eras in which we find those speeds. Given that definition, trans-temporality is clearly found in our construction of our knowledge production systems and within them the universities and similar environments. These knowledge environments both produce, archive, and project knowledge across times and speeds through systems of learning and memory are built not only in the people who inhabit those institutions, but also within the infrastructures of the institutions(Hunsinger, 2009a; Hunsinger, 2009b).

I am not arguing that the institutions of knowledge production are in any way separable from neoliberal or hypercapitalist systems, instead I argue that if the problems of our institutions of knowledge production are derivatives of the ideology of speed cosmopolitanism and its relation to the systems and processes related to those ideologies, then perhaps there is a way forward that transforms those ideologies(Olssen \& Peters, 2005; Olssen, 2006). In much the same way that the mass production of folio books transformed the ideologies of speed of the learning found in lectures prior to mass production was resisted by the institution of the lecture and the university credit system, we can transform learning and knowledge production systems in resistance. (Agger, 1988). We can look to prior transformations of speed in relation to learning to discuss new issues of speed and learning(Agger, 2004; Virilio, 1986).

We construct our systems of knowledge production, our markets and their ideologies such as neoliberalism, hypercapitalism and speed cosmopolitanism discursively and performatively through our everyday lives within capitalism and within its complicit institutions such as the university(Fairclough, 1992; Lemke, 2007). That the university as a system of knowledge production is complicit in these ideologies should be clear from its changing structures, its growing managerialism, and its accelerational goals. We as the people who co-construct our institutions both discursively and performatively, could construct the university to be different by changing our practice and creating new institutions. Given that some professors want to attempt to carve out this sort of subaltern from within the hegemonic neoliberal university, they should also realize that like almost every other educational movement in higher education; any subaltern will eventually become complicit within and accounted for by the systems of hypercapitalism and speed cosmopolitanism. Each new program becomes a new market for speed and accelleration, so long as we allow those ideologies to promulgate.

This promulgation of ideology combines with our machinic, computational subjectivity and recreates us and our institutions as elements of the ideology itself. We can resist it, but neoliberalism, hypercapitalism, and speed cosmopolitanism are not the only ideological construct we are facing. All three go hand-in-hand with an element of biopolitics, which is bureacratism, which in the accellerated form might be thought of as hyperbureauctratism and hyperbureaucratization. 


\section{From Hypercapitalism to Hyperbureaucratism}

If we think, as professors, that the modern university is under attack by the neoliberal, hypercapitalist knowledgeoriented robber barons, then as a class we are self-deceiving. While this narrative gives us an externality to resist which is not based in the complicities of ourselves within the universities, it is also not revelatory of the actual conditions of our complicity in our own condition. It is not only the outside of the university bringing about this transformation, but it us, within the university that enables the transformation. What we have is the faculties, the central bodies of the university system, becoming disempowered through their own self constructed interests of wanting less work in the face of the mounting workload of the bureaucratic environments being imposed upon by the system of governance as founded in legislative and juridical arenas.(Adorno, 2001; Foucault, 2008) This ballooning bureaucratic workload needs balanced by the professoriate against their related goals of service, teaching, and research.

In the face of the ever increasing workload, the ideology of speed cosmopolitanism requires speedy resolution of the bureaucratic requests originating both from within and outside of the university. The ideology of speed requires the requests to be removed from the arena of faculty decision with its implicit slowness of consideration and moved into the new efficient academic bureaucracy. By necessity the bureaucracy grows exponentially in relation to the increasing workload, increasing budgets, and in the end requiring even more faculty oversight, which faculty no longer have time to provide(Essaji \& Horton, 2010; Vest, 2007). The tension between the growth of university bureaucracy and the increasing workload of faculty is the essential driver of the transition toward the death of the university in its contemporary and nostalgic forms. In its place will be born, if the managerial class continues to flourish, a new series of service oriented knowledge production centers where a former member of a university faculty will now be a for contract service provider at either: a learning oriented service center, which provides basic credentializaton of the population as its teaching core; a research oriented service center which provides research on demand for anyone that will pay; or a community oriented service center which will apply the knowledge of highly specialized services workers to specific problems for people who can pay. All of this will be managed by a class of managers far removed from the experiences of the service provider, but work to ensure the quality of the programs through systemically abstracted evaluative metrics. This is one predictive story of how the hypercapitalist university becomes the hyperbureaucratic university, which in terms eventually becomes nothing more than a hyperbureaucratic service provider.

The university is always and has always been a place of struggle between governance and knowledge production. The current struggle centers on the implications of the required workloads of governance and knowledge production. Faculties are frequently engaged in everything other than confronting their own governance and thus become complicit in schemes to make their own lives and systems of knowledge production more efficient, more bureaucratized, and more capitalized(Rutherford, 2005; Nowotny, Scott, \& Gibbons, 2001; Slaughter \& Rhoades, 2004). The mode of resistance is not to revolutionize the university, but contrarily to deny the acceleration culture and the ideology of speed cosmopolitanism driving the revolution.

\section{Slow Science and the Slow University}

Virtually all slow movements are resistances to speeded-up qualities of life (Carp, 2012) 104

Acceleration culture and the ideology of speed cosmopolitanism are not new in academia nor is it new in the North American research context. Bertrand Russell was confronted with what he perceived as the culture of "quick results" at Harvard University, which is why he decided not to join that university.

But if Russell liked, even admired, the students, he had little good to say about the faculty, which persisted in trying to recruit him. "Dull," "tiresome," "complacent" people, forced to spend themselves in endless teaching and to produce "quick results," they were deprived of the "patient solitary meditation...that go[es] to producing anything of value." They lacked, he said, "the atmosphere of meditation and absent-mindedness that one associates with thought-they all seem more alert and businesslike and punctual than one expects very good people to be." Above all, it was the "blind instinctive devotion to ideals dimly seen" that Russell missed, "regardless of whether they are useful or appreciated by others."(Bailyn, 1991)

What Russell was indicating was the virtual blindness toward knowledge caused by the culture of quick results 
and the related acceleration culture around academic knowledge production. That Bertrand Russell crossed the Atlantic to be confronted with such problematic circumstances is not surprising, because by then the systems of knowledge production were cosmopolitan.

Russell did not end his critique of that well regarded institution of higher learning. Baylin continues the description of what Russell thought of the President of the university thusly:

Lowell was determined, Russell wrote, "to get his money's worth out of [the faculty] and throw them on the scrap heap when they are used up." Under Lowell's administration, he wrote, "this place is Hell." The only remedy for Lowell's "hard slavedriving efficiency," his "loathsome" regime, Russell believed, was a reversal of precisely those developments of the early eighteenth century that had come to distinguish Harvard and other American colleges and universities from the pattern of the ancient colleges he knew so well.(Bailyn, 1991)

We can see the same responses amongst faculty today. University administrations are attempting to maximize profits from faculty labors as part of the need to be fact, the need to compete, the need to participate in the marketplace of higher education and research. The university and its faculty do not have to compete, we do not need to maximize profits, and we do not need to perpetually compare ourselves to others in order to justify our existence. What we need to do in order to justify our existence is to produce communities that generate knowledge.

Knowledge needs time, science needs time and to that end some scientists have put forth a manifesto which is emblematic of some of the problems faced by researchers these days:

\section{THE SLOW SCIENCE MANIFESTO}

We are scientists. We don't blog. We don't twitter. We take our time.

Don't get us wrong - we do say yes to the accelerated science of the early 21st century. We say yes to the constant flow of peer-review journal publications and their impact; we say yes to science blogs and media \& PR necessities; we say yes to increasing specialization and diversification in all disciplines. We also say yes to research feeding back into health care and future prosperity. All of us are in this game, too.

However, we maintain that this cannot be all. Science needs time to think. Science needs time to read, and time to fail. Science does not always know what it might be at right now. Science develops unsteadily, with jerky moves and unpredictable leaps forward-at the same time, however, it creeps about on a very slow time scale, for which there must be room and to which justice must be done.

Slow science was pretty much the only science conceivable for hundreds of years; today, we argue, it deserves revival and needs protection. Society should give scientists the time they need, but more importantly, scientists must take their time.

We do need time to think. We do need time to digest. We do need time to misunderstand each other, especially when fostering lost dialogue between humanities and natural sciences. We cannot continuously tell you what our science means; what it will be good for; because we simply don't know yet. Science needs time.

-Bear with us, while we think. (http://slow-science.org/)

Slowness works for knowledge, slowness works for science(Pels, 2003). It does not have to be super-slowness, but it has to be the slowness of knowledge and science that actually is prudent for the world in which we live, that world's futures. We need time to read, time to think, time to reflect and time to come to know. We need time to make knowledge work on the human scale and our ecological scales.

If knowledge takes time to create and time to process on a human scale, why are we pushing both faculty and students to do more with less? Why are we forcing our students to not be able to learn in our classes by forcing them to learn according to schedules which do not actually map onto their possible timeframes for coming to know? It is because we are caught in a series of ideologically biased traps about time and capital. These traps all assume knowledge is fast, but only people who can actually move fast, strategically are those that actually taken the time to come to their knowledge, or those that deny the benefit of knowledge, though the latter could hardly be called strategic. The ideologies of speed cosmopolitanism and acceleration culture in knowledge production as such should be thought of as a deceit driven by ignorance of the system of knowledge production. Beyond being deceipt, these ideologies also are creating unreal and impossible conditions for the creation of that knowledge for all learners.

The university is not traditionally a place of teaching, it is a place of learning; a place that houses our professional learners which are called professors. This focus on learning is key differentiation that defines the nature of the community of learning that is the university. Teaching, if it happens at a university, is only in service of learning. 
Our learning goes beyond the mere gaining of knowledge and then representing it. Our learning is about learning to construct new knowledges. We base much of this learning to construct new knowledges by learning models of old knowledge's constructions. The intimate knowledge of our processes of knowledge construction allows us to trust what we know. For unless we actually know the processes of knowledge production, we cannot really know the knowledge is legitimate, nor can we really understand the knowledge at all. Without that learning, we can only trust the authority which is presenting us with claims to knowledge, which may or may not be someone who actually is an authority on the subject. This focus on authority undermines our professors, who do not traditionally rely on the mediated authority structures that our students are presented on television, nor necessarily the authority structures of the traditional elementary and secondary schools.

Similarly the novice learners or students students need to be able to move beyond those models of authority and into the systems and processes of knowledges focussed on enabling them develop the capacity to recognize the legitimation of knowledge which is found in the practices of knowledge. Our students need time; they need to slow down, to focus on their work, and to practice their knowledge processes. They do not need a prepackaged informational system that may not be anything more than they can read on the internet such as those in moocs. Our students need time, because science takes time and all modes of research take time. Time is consistently poached from the researching and learning in order for the time to be placed in administrative tasks or placed in teaching tasks. As professional learners, professors know knowledge takes time, research takes time, and students need time to learn those processes.

Since knowledge and learning are slow and require time, perhaps we need to promote the idea of a slow university. One conception of a slow university arises in conjunction with the slow food movement, that movement attempts to resist the acceleration of food culture into a homogeneous normality of blandness in order to instead celebrate the unique food traditions, flavours, and regional identities that arise from living local, cooking slow, and eating slow. Their university is the University of Gastronomic Science, which much like the food it supports, supports slow learning and depth of learning over the speed of production of the neoliberal institutions which would prefer to graduate students in scheduled fashion.

However, the slow food movement is not the only model of a slow university, Warsaw also has its slow university, their motto as an autonomous, nomadic university is, "Freedom through slowness". Speed and acceleration will inevitably cause us to be trapped in a race to the finish where we do not determine the terms of the race or the finish, and thus we must always lose.

Knowledge production should not be seen to be a race to be won or lost as it is in the speed cosmopolitanism of the hypercapitalist/hyperbureaucratized university, it should be about the generation of knowledge in communities that require it. This situation requires an education system that generates and sustains the knowledge production system. This is also one of the real reasons why universities are also institutions that teach students. This education system should also be predicated on admitting that knowledge production and acquisition is slow, is fluxing, and entirely dependent on trans-temporalities of the knowledge system. Education whether fast or slow is not a game of achievements or check-boxes; it is about life improvement and the opening of possible trajectories for that life(Illich, 1971). Education is also about joining a community of knowledge that is dedicated to learning about a topic. Slow education as described as part of a sustainability movement in Japan is described in terms of developing a good life that is embedded in its community.

SLOW EDUCATION: We pay less attention to academic achievement, and create a society in which people can enjoy arts, hobbies, and sports throughout our lifetimes, and where all generations can communicate well with each other.(2003)

The ability to communicate knowledge across communities is part of the legitimizing system of knowledge and the only solution to the problem of legitimation of knowledge in the slow university. (Habermas, 1975; Lyotard, 1984; Hunsinger, 2005) The capacity to enjoy knowledge and to love it is also part of the good life. That enjoyment is also necessary for the good of our communities and for us to have good lives together. By slowing education down and allowing students the freedom to find what they love to learn and what they will learn to love, we can transform the slow university through slow education, thus transforming the university from a system of individualized instruction based on personal achievements to a system of community learning based on the development of good communities (of knowledge, of people, of things) and people participating in those communities. With the communities will arise the new systems of legitmation needed to sustain those communities and thus to sustain slow education and the slow university. 


\section{Slowness as Tenant: a Conclusion}

The Slow movement connects people to the material conditions of existence in a way that informs and honors their relationship to their everyday surroundings. The lived experience of the senses, of personal reciprocity and exchange, of cultural diversity and history and sense of place, of health and well-being is engaged with respect to a particular social, cultural, and ecological context. The Slow movement articulates the interrelationship among natural resources, the process of making (whether it be music, sense, love, or cheese), and use. (Carp, 2012) 105

Our world does not need needs to be fast. Being fast does not improve our world. It is that people do not resist the fast. In this paper, I propose that we resist the fast, that we slow down. By slowing down, I want us to have more time to think, not just think individually, but to think as a community. Knowledge as I have argued in this paper is slow, and its central processual tenant is its slowness. If we run into fast knowledge or the demand for speed within knowledge production, we should slow down. we should go slow, be skeptical,and consider why someone wants something fast and think about what the implications of speed for that knowledge will be for everyone. We should not transform our subjectivities toward knowledge and its legitimation in relation to speed cosmopolitanism. We need to de-daemonize/de-mechanize our subjectivities in relation to knowledge systems. The implications of speed cosmopolitanism and its resistance, as I have argued, are going to be far broader than we can individually think. If we stop and take the time to discuss the knowledge, to actually generate the knowledge and its reflexive positions in our communities, we stand a chance to develop a system of knowledge production that can actually resist the nihilism of acceleration; that will recognize and promote our values. This type of system is possible both for the internet and the university.

\section{References}

Adorno, T. W. (2001). The culture industry: Selected essays on mass culture ( 2 ed.). Routledge.

Agger, B. (1988). Fast capitalism. University of Illinois Press.

Agger, B. (2004). Speeding up fast capitalism: Cultures, jobs, families, schools, bodies. Paradigm Publishers.

Bailyn, B. (1991). Fixing the turnips. Harvard Magazine, March-April.

Beck-Gernsheim, E., \& Beck, U. (2002). Individualization: Instituitionalized individualism and its social and political consequences. Sage Publications.

Beck, U. World risk society. Logos, 4.

Beck, U. (1992). Risk society : Towards a new modernity. Sage Publications.

Carp, J. (2012). The study of slow. In B. E. Goldstein (Ed.), Collaborative resilience: moving through crisis to opportunity. Cambridge, MA.: MIT Press.

Essaji, A., \& Horton, S. (2010). Silent escalation: Salaries of senior university administrators in ontario, 1996-2006. Higher Education, 59(3), 303-322.

Fairclough, N. (1992). Discourse and social change. Polity Press.
Feldman, R. M., \& Feldman, S. P. (2006). What links the chain: An essay on organizational remembering as practice. Organization, 13(6), 861-887.

Foucault, M. (2008). The birth of biopolitics: Lectures at the college de france, 1978-1979. Palgrave Macmillan.

Gates, B. (1999). Business at the speed of light. Warner Books.

Gleick, J. (2000). Faster: The acceleration of just about everything. Vintage.

Graham, P. (2001). Hypercapitalism: An investigation into the relationship between language, new media, and social perceptions of value. Queensland University of Technology, Brisbane, Australia.

Guattari, F. (1995). Chaosophy. Semiotext(e).

Guattari, F. (1996). Soft subversions. Semiotext(e).

Habermas, J. (2000). The postnational constellation. Polity Press.

Habermas, J. (1975). Legitimation crisis. Beacon Press.

Hunsinger, J. (2009a). Introducing learning infrastructures: Invisibility, context, and governance. Learning Inquiry, 3(3), 111-114.

Hunsinger, J. (2005). Toward a transdisciplinary internet research. The Information Society, 21(4), 277-279. 
Hunsinger, J. (2009b). Toward nomadological cyberinfrastructures. In J. Hunsinger, L. Klastrup, \& M. Allen (Eds.), International Handbook of Internet Research. Netherlands: Springer.

Illich, I. (1971). Deschooling society. New York.

Jennings, J., \& Haughton, L. (2002). It's not the big that eat the small.It's the fast that eat the slow: How to use speed as a competitive tool in business. HarperBusiness.

Lemke, J. (2007). Textual politics: Discourse and social dynamics.

Lyotard, J.-. (1984). The postmodern condition: A report on knowledge. University of Minnesota Press.

Massumi, B. (2005). Fear (the spectrum said). positions, 13(1), 31- 48 .

Nowotny, H., Scott, P., \& Gibbons, M. (2001). Re-thinking science: Knowledge and the public in an age of uncertainty. Polity Press.

Olssen, M. (2006). Understanding the mechanisms of neoliberal control: Lifelong learning, flexibility and knowledge capitalism. International Journal of Lifelong Education, 25(3), 213-230.

Olssen, M., \& Peters, M. A. (2005). Neoliberalism, higher education and the knowledge economy: From the free market to knowledge capitalism. Journal of Education Policy, 20(3), 313-345.
Pedersen, M. A., \& Nielsen, M. (2013). Trans-temporal hinges: Reflections on an ethnographic study of chinese infrastructural projects in mozambique and mongolia. Social Analysis, 57(1), 122-142.

Pels, D. (2003). Unhastening science temporal demarcations in the 'social triangle'. European Journal of Social Theory, 6(2), 209-231.

Reid, H. G. (1978). Totality, temporality, and praxis: Existential phenomenology and critical political theory. Canadian Journal of Political and Social Theory, 2(1), 113-135.

Rutherford, J. (2005). Cultural studies in the corporate university. Cultural Studies, 19(3), 297-317.

Slaughter, S., \& Rhoades, G. (2004). Academic capitalism and the new economy: Markets, state, and higher education. The Johns Hopkins University Press.

(2003). The 'slow life' movement: Happiness before economic efficiency. Japan for Sustainability.

Vest, C. M. (2007). The american research university from world war ii to world wide web: Governments, the private sector, and the emerging meta-university (1). Univ of California Press.

Virilio, P. (1986). Speed and politics: An essay on dromology. SemioText. 